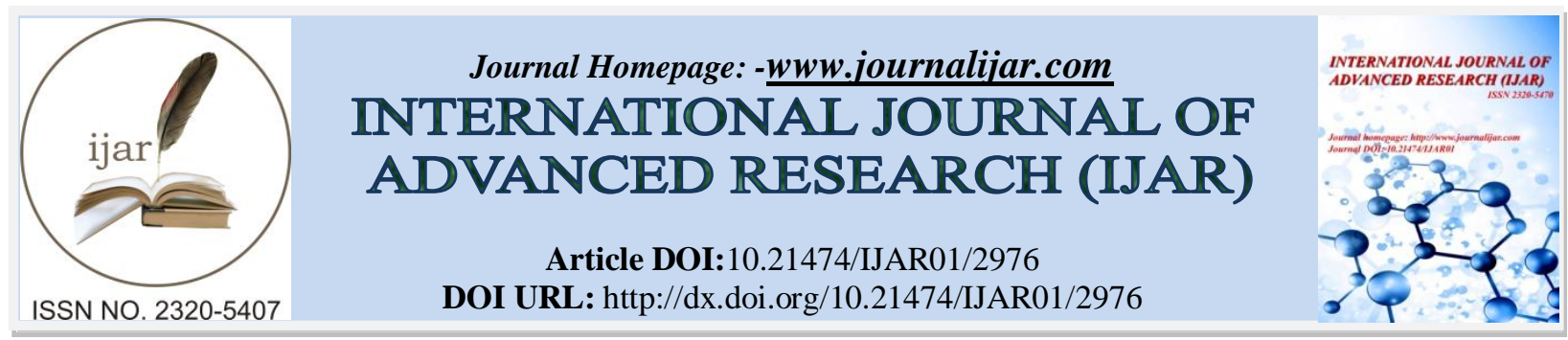

RESEARCH ARTICLE

\title{
EFFECT OF FRICTION STIR PROCESSING PARAMETERS ON THE TENSILE STRENGTH OF SURFACE COMPOSITE ALUMINUM ALLOY.
}

Essam Moustafa $^{1}$, Samah Mohammed ${ }^{2}$, Sayed Abdel-Wanis ${ }^{2}$ Tamer Mahmoud $^{2}$ and El-Sayed El-Kady ${ }^{2}$ 1. Faculty of Engineering, King Abdul Aziz University, KSA.

2. Faculty of Engineering (Shoubra), Benha University, Egypt.

\section{Manuscript Info}

Manuscript History

Received: 26 November 2016

Final Accepted: 27 December 2016

Published: January 2017

Key words:-

FSP, Surface, Composite, tensile, strength, processing

\section{Abstract}

In the current study, the surface composite sheet of AA2024/al203 has been fabricated using friction stir processing technique. The processing parameters during fabrication process; such as rotation speed, travel speed and number of passes have been investigated. The number of passes has a significant effect on the mechanical properties through tensile test. The results revealed that tensile strength improved with increasing passes number.

Copy Right, IJAR, 2016,. All rights reserved.

\section{Introduction:-}

Increasing demand for improving the properties of surfaces in order to meet with design and functional requirements. Friction stir processing (FSP) is one of the techniques for fabricating surface composites and modifying microstructural features, furthermore the improvement of mechanical properties. Process parameters are the key art of Friction Stir Processing. The stirring conditions (rotational and translational speeds) are important issues in FSP to obtain the desired mechanical properties.

Many researchers were discussed the relation between the process parameters and the quality of welded or processed metals according to $\left[{ }^{1,2,3,4}\right]$. The Tensile strength is found to be increased with increasing the rotational speed up to specified limit for AA6351 Al alloys as reported by $\left[^{5}\right]$. The tensile properties and fracture locations have been investigated by many authors $[6,7,8]$ they are fabricated metal sheets alloy using FSP. The results are revealed that the rotational speed has a significant influence on the tensile strength as a result of improving grain refinement of the material. The mechanisms of particle refinement during FSP of pure Al, and the effect of various processing parameters on the particle refinement have been studied by $\left[{ }^{9}\right]$. The investigators reported, that amount of heat generation during FSP was increased when rotational speed increase and decrease when transverse speed increase. Fabricating AA1050/SiC surface composite using FSP technique has been investigated by $\left[{ }^{10}\right]$ the author concluded that , the formation of defects are causing at higher tool rotational speeds. The surface composite sheets are investigated by $\left[{ }^{11,12,13,14,15,16}\right]$, they are concluded that tool rotation speed has a major effect on the mechanical properties and microstructure refinement.

The effect of multi-pass FSP on the, microstructure, micro hardness and tensile strength on the metal alloy and composites have been studied by $\left[{ }^{17,18,19,20,21,22}\right]$.Multi pass FSP not only improve the mechanical properties, but also get defect-free weld through adjusting the Welding parameters, including tool rotation rate, traverse speed, spindle tilt angle, and target depth $\left[{ }^{23}\right]$. multi-pass with even step (2, 4 up to 8-pass) FSP with $100 \%$ overlap was performed by $\left[{ }^{24}\right]$ The results reported that multi-pass FSP were improved tensile properties of composites including UTS, yield strength (YS) and elongation. The authors were reasoned this improvement because of reduced 
porosity contents.CNT/2009Al is fabricated by combination of Powder Metallurgy and FSP by [ ${ }^{25}$ ]. It was observed that as the FSP passes increased, there was good dispersion for CNT in the matrix, and the maximum tensile strength increased with increasing the passes number.

In the current investigation the aim of this work is to fabricate a surface composite sheet from AA2024 aluminum sheet and alumina nanoparticles, in order to enhance the tensile properties though overlap multi pass friction stir processing.

\section{Experimental work:-}

The wrought alloy sheets of AA2024 has been prepared and the Annealing is done at $410{ }^{\circ} \mathrm{C}$ for 2 hours, followed by slow cooling in the furnace to relief the remaining residuals stresses after clod and hot sheet metal working and improve ductility and dimensional stability. A rectangle slotted groves are machined in each plate. The alumina nanoparticles are filled the grooves, then the friction stir processing has been carried out to fabricate the desired surface composite. The chemical composition for AA2024 wrought alloy is given in (Table 1). An automatic milling machine is used to perform FSP at different combination of processing parameters. The tool rotation speed was vary at different four rotation speed 900, 1100, 1500, $1800 \mathrm{rpm}$. Processing travel speed was chosen at three speeds $(10,15$, and 20$) \mathrm{mm} / \mathrm{min}$, the last factor that effect on the process is the number of passes, and it is design to be processed at three overlap level.

Table 1:- Chemical composition of the as received AA2024 alloy (weight \%)

\begin{tabular}{|l|l|l|l|l|l|l|l|l|}
\hline Element & $\mathrm{Cu}$ & $\mathrm{Mg}$ & $\mathrm{Mn}$ & $\mathrm{Zn}$ & $\mathrm{Fe}$ & $\mathrm{Si}$ & $\mathrm{Pb}$ & $\mathrm{Al}$ \\
\hline$\%$ & 4.89 & 1.45 & 0.616 & 0.156 & 0.11 & 0.107 & 0.0193 & Remain \\
\hline
\end{tabular}

\section{Tensile Test:-}

Tension test has been performed by MTS machine as shown in "Fig. 1". According to ASTM B557 with standard specimens along the processing zone as shown in "Fig. 2". The samples are tested in order to evaluate the tensile properties such as young's modulus, ultimate tensile strength (UTS) and yield stress (YS).
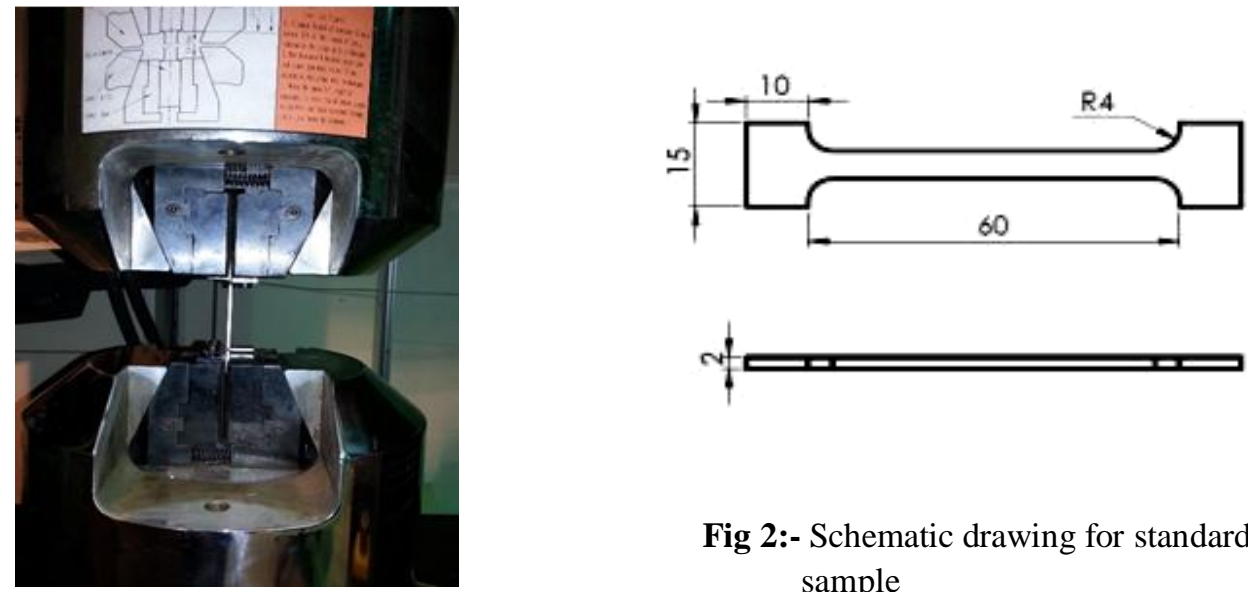

Fig 2:- Schematic drawing for standard tension test sample

Fig 1:- Universal tension test machine

\section{Results and Discussions:-}

The mechanical properties and material flow pattern are influenced with the Processing parameters such as tool rotation speed, longitudinal traverse speed and number of passes. The tool rotation speed effect on the tensile stress, but the ductility is decreased by $50 \%$ with respect to the base metal as shown in "Fig.3". As-received alloy has the highest elongation. The results reveal that, although the addition of $\mathrm{Al}_{2} \mathrm{O}_{3}$ Nano powder increases the strength, it decreases the ductility which it was congruent with $\left[{ }^{26}\right]$. 


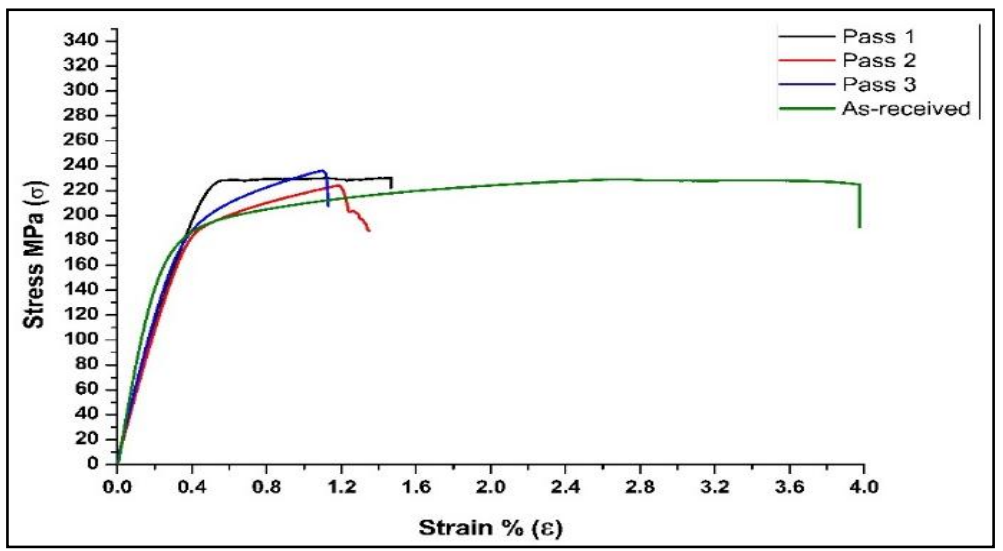

Fig 3:- Tensile strength samples tested at $900 \mathrm{rpm}$ with $10 \mathrm{~mm} / \mathrm{min}$ travel speed

Higher tool rotation speed increases the heat produced during friction stirring action, the high temperature in this metal matrix causes defects during processing specially in the first pass. The rotation speed $1500 \mathrm{rpm}$ and $1800 \mathrm{rpm}$ resulting poor surface composite. The tensile strength curves show preference of low rotation speed rather than using higher speeds as shown in "Fig.4" and "Fig.5". The first pass noticed that, it is insufficient to improve the mechanical properties because some voids or defects are remained in the matrix. These results are in accordance to the previous results $\left[{ }^{27,28,29,30}\right]$.

Enhanced results for these metal matrixes composite are obtained at relatively low speeds with $10 \mathrm{~mm} / \mathrm{min}$ and 15 $\mathrm{mm} / \mathrm{min}$ traverse speed as shown in "Fig. 6". The improvement in the surface tensile properties is explained due to provide the sufficient heat during stirring process.

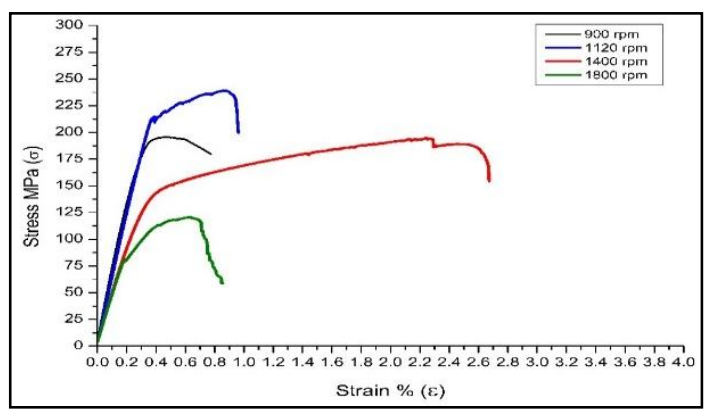

Fig 4:- Effect of rotational speed on tensile strength at $10 \mathrm{~mm} / \mathrm{min}$ travel speed for the $1^{\text {st }}$ pass.

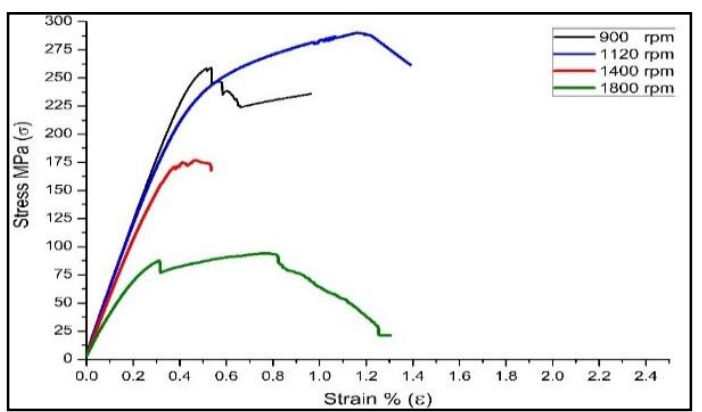

Fig 5: -Effect of rotational speed on tensile strength at 15 $\mathrm{mm} / \mathrm{min}$ travel speed for the $1^{\text {st }}$ pass

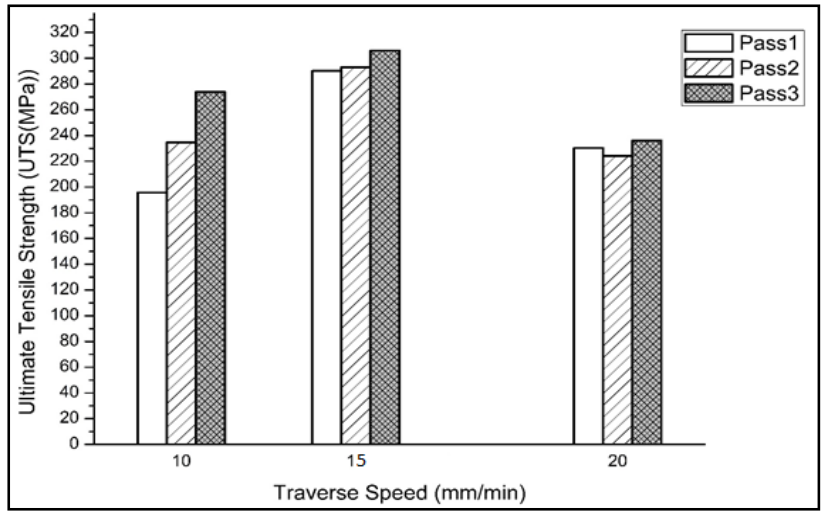

Fig 6:- Effect of traverse speed on the ultimate tensile strength at constant rotation speed $900 \mathrm{rpm}$. 
Ultimate tensile strength (UTS) results are represented in the comparison curves which, illustrates the effect of rotation speed on the ultimate tensile strength throughout different passes number as shown in "Fig.7" and "Fig. 8". Tool rotations speed performed at 900-rpm and 1100-rpm have a higher ultimate tensile strength than other speed specially when processed at $10 \mathrm{~mm} / \mathrm{min}$ and $15 \mathrm{~mm} / \mathrm{min}$ traverse speeds. Third pass causes an improvement in the tensile strength which, the maximum value for UTS is improved by $27 \%$ rather than base metal. Tool rotation speed at 1800-rpm remarked that, having a lower UTS.

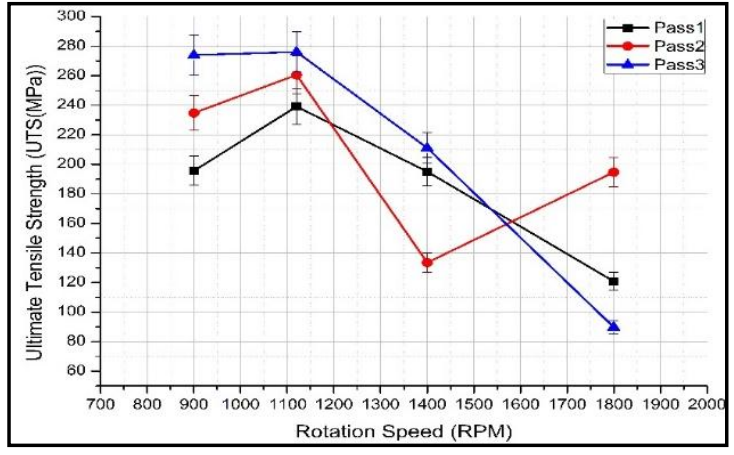

Fig 7:- Effect of rotational speed on UTS at $10 \mathrm{~mm} / \mathrm{min}$ travel.

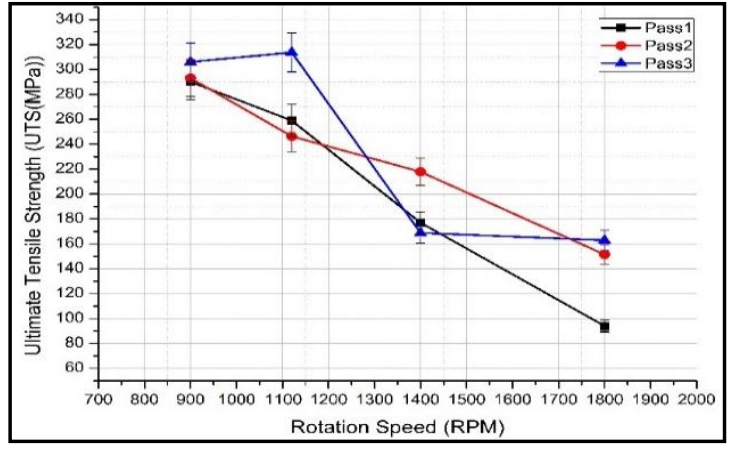

Fig 8:- Effect of rotational speed on UTS at 15 $\mathrm{mm} / \mathrm{min}$ travel.

\section{Conclusion:-}

This paper present the effect of processing parameters on the tensile properties of surface composite alloy fabricated by friction stir process. The results are concluded that:

- The average tensile strength of friction stirring processed specimen are improved by $10 \%$ as compared to the base metal

- The ductility of resultant metal matrix composite was decreased by $50 \%$ due to presence of alumina particles in the matrix.

- The superior tensile strength is achieved at low rotational speeds of 900-rpm and 1100 -rpm with medium travel speed $15 \mathrm{~mm} / \mathrm{min}$.

- Increasing the number of FSP passes lead to refinement the grain, furthermore good distribution of alumina nanoparticles in the composite matrix.

\section{References:-}

1. K. Hussain and S. A. P. Quadri, "Evaluation of parameters of friction stir welding for aluminum AA6351 alloy," International Journal of Engineering Science and Technology, vol. 2(10), pp. 5977-5984, 2010.

2. M. JAYARAMAN and V. BALASUBRAMANIAN, "Effect of process parameters on tensile strength of friction stir welded cast A356 aluminium alloy joints," Transaction of Nonferrous Metal scocity of china, vol. 23, p. 605-615, 2013. S.

3. Rajakumar and V. Balasubramanian, "Establishing relationships between mechanical properties of aluminium alloys," Materials and Design, vol. 40, p. 17-35, 2012.

4. Devaraju , A. Kumar and A. Kumaraswamy, "Influence of reinforcements (SiC and Al2O3) and rotational speed on wear and mechanical properties of aluminum alloy 6061-T6 based surface hybrid composites produced via friction stir processing," Materials and Design, vol. 51, p. 331-341, 2013.

5. S. N. S. Y.J. Kwon, "Mechanical properties of fine-grained aluminum alloy produced by friction stir process," Scripta Materialia, vol. 49, p. 785-789, 2003.

6. M. G. G.Venkateswarlu, "Effect of Rotational Speed on Microstructure and Mechanical Properties of Friction Stir Processed Mg AZ31B Alloy," International Conference On Advances In Engineering, Science And Management, pp. 323- 327, 2012.

7. O. S. Salih, H. Ou , W. Sun and D. G. McCartn, "A review of friction stir welding of aluminium matrix composites," Materials and Design, vol. 86, p. 61-71, 2015. 
8. H. J. LIU, "Friction stir welding characteristics of 2017-T351 aluminum alloy sheet," JOURNAL OF MATERIALS SCIENCE, vol. 40, p. 3297 - 3299, 2005.

9. R. Moshwan , F. Yusof and M. A. Hass, "Effect of tool rotational speed on force generation, microstructure and mechanical properties of friction stir welded Al-Mg-Cr-Mn (AA 5052-O) alloy," Materials and Design, vol. 66, p. 118-128, 2015.

10. M. H. Wais, J. . M. Salman and A. . O. Al-Roubaiy, "Effect Of Friction Stir Processing On Mechanical Properties And Microstructure Of The Cast Pure Aluminum," International Journal Of Scientific \& Technology Research, vol. 2, no. 12, pp. 154-163, 2013.

11. E. R. Mahmoud, K. Ikeuchi and M. Takahashi, "Fabrication of SiC particle reinforced composite on aluminium surface by friction stir processing," Science and Technology of Welding and Joining, vol. 13, no. 7, pp. 607-608, 2008.

12. D. K. Lim, T. Shibayanagi and A. P. Gerlich, "Synthesis of multi-walled CNT reinforced aluminium alloy composite via friction stir processing," Materials Science and Engineering A, vol. 507, p. 194-199, 2009.

13. P. Asadi, M. K. Besharati Givi, K. Abrinia, M. Taherishargh and R. Salekrostam, "Effects of SiC Particle Size and Process Parameters on the Microstructure and Hardness of AZ91/SiC Composite Layer Fabricated by FSP," Journal of Materials Engineering and Performance, vol. 20, no. 9, p. 1554-1562, 2011.

14. Thangarasu, N. Murugan, I. Dinaharan and S. J. Vijay, "Effect of tool rotational speed on microstructure and microhardness of AA6082/TiC surface composites using friction stir processing," Applied Mechanics and Materials, Vols. 592-594, pp. 234-239, 2014.

15. Kurta, I. Uygurb and E. Cetec, "Surface modification of aluminium by friction stir processing," Journal of Materials Processing Technology, vol. 211, no. 3, p. 313-317, 2011.

16. M. Azizieh, A. H. Kokabi and P. Abachi, "Effect of rotational speed and probe profile on microstructure and hardness of AZ31/A12O3 nanocomposites fabricated by friction stir processing," Materials and Design, vol. 32, p. 2034-2041, 2011.

17. R. Sathiskumar, . I. Dinaharan, N. Murugan and S. J. VIJAY, "Influence of tool rotational speed on microstructure and sliding wear behavior of $\mathrm{Cu} / \mathrm{B} 4 \mathrm{C}$ surface composite synthesized by friction stir processing," Transaction of Nonferrous Metal scocity of china, vol. 24, p. 95-102, 2014.

18. W. T. A. R. Rebecca Brown, "Multi-pass friction stir welding in alloy 7050-T7451: Effects on weld response variables and on weld properties," Materials Science and Engineering A, Vols. 513-514, p. 115-121, 2007.

19. H. ,. M. ,. A. S. Sahraeinejad, "Fabrication of metal matrix composites by friction stir processing with different Particles and processing parameters," Materials Science \& Engineering A, vol. 626, p. 505-513, 2015.

20. M. SarkariKhorrami, M. N. Kazeminezhad and A. H. Kokabi, "The effect of SiC nanoparticles on the friction stir processing of severely," Materials Science \& Engineering A, vol. 602, p. 110-118, 2014.

21. S. Panigrahia, K. Kumara and W. Yuana, "Transition of deformation behavior in an ultrafine grained magnesium alloy," Materials Science and Engineering A, vol. 549, p. 123- 127, 2012.

22. W. Yuan, S. Panigrahi and R. Mishra, "Influence of grain size and texture on Hall-Petch relationship for a magnesium alloy," Scripta Materialia, vol. 65, p. 994-997, 2011.

23. Mishra, Rajiv Sharan, Partha Sarathi and N. Kumar, Friction Stir Welding and Processing, Switzerland: Springer International Publishing, 2014.

24. M. Barmouz and M. Kazem Besharati Givi, "Fabrication of in situ $\mathrm{Cu} / \mathrm{SiC}$ composites using multi-pass friction stir processing: Evaluation of microstructural, porosity, mechanical and electrical behavior," Composites: Part A, vol. 42, p. 1445-1453, 2011.

25. X. W. W. ,. Z. M. Z.Y. Liu, "Analysis of carbon nanotube shortening and composite strengthening in carbon nanotube/aluminum composites fabricated by multi-pass friction stir processing," carbon, vol. 69, p. $264-27$ 4, 2014.

26. L. Johannes and R. Mishra, "Multiple passes of friction stir processing for the creation of superplastic 7075 aluminum," Materials Science and Engineering A, vol. 464, p. 255-260, 20017.

27. Z. Z. Y. Z. G. C. Y. G. M. L. J. Z. Rui Yang, "Effect of multi-pass friction stir processing on microstructure and mechanical properties of Al3Ti/A356 composites," Materials Characterization, vol. 106, p. 62-69, 2015.

28. Z. Da-Tong, X. Feng and Z. Wei-Wen, "Superplasticity of AZ31 magnesium alloy prepared by friction stir processing," Trans. Nonferrous Met. Soc. China, vol. 21, p. 1911-1916, 2011.

29. P. Cavaliere and P. De Marco, "Superplastic behaviour of friction stir processed AZ91 magnesium alloy produced by high pressure die cast," Journal of Materials Processing Technology, vol. 184, p. 77-83, 2007.

30. S. Tutunchilar, M. Besharati Givi and M. Haghp, "Eutectic Al-Si piston alloy surface transformed to modified hypereutectic alloy via FSP," Materials Science and Engineering A, vol. 534, p. 557- 567, 2012. 